"Es falso decir: yo pienso. Se debería decir: me piensan". Esta sentencia de Rimbaud nos parece adecuada para iniciar el tema que nos reúne; es decir aquel que nos interroga sobre la limitación de la intervención en el patrimonio, en orden a rentabilizar económicamente las actuaciones sobre el mismo. No trataré, por tanto, un modo de pensar el patrimonio desde un punto de vista ecológico, es decir, el que cabría construirse en torno a una idea de la historia como paisaje, como aire, como sustento de nuestra conciencia, sin que ello se vincule a los circuitos de la producción económica. Por el momento, ese patrimonio, esa ecología, no creemos que debiera excluirse. Una consideración de nuestro entorno histórico, que ante la demanda de rentabilidad, interroga sobre la funcionalidad de aquel, debería siempre pasar por el "tiempo muerto" que hasta ese momento ha venido ocupando, ofreciendo el recreo por entre las piedras, entre las páginas, entorno a los paisajes, pues la definición de patrimonio es así de amplia. Patrimonio es la ecología del "pensamos" en un entorno que nos pertenece, que nos ata a un tiempo, que nos ofrece la conciencia de la colectividad en su más pura definición. Quisiera dejar esta cuestión aquí sólo para equilibrar por el momento, una propuesta de revitalización de patrimonio, sin duda necesaria, pero que siempre deberá, a mi entender, contrapesarse con esta noción de patrimonio exento del pecado de los "tiempos modernos". Que alguien nos libre de una interpretación de estas palabras como si esta definición de nueva ecología fuera un nuevo reaccionarismo. Durante mi corta intervención, quedará clara mi posición sobre la actuación en el patrimonio. Si contribuyo a sembrar la ambigüedad y a esbozar interrogantes, creo que estaremos en un buen punto de arranque no sólo para pensar esa historia común de todos que es el patrimonio, sino para concienciarnos sobre nuestra inevitable parcialidad cuando miramos el pasado, y desde luego el presente. Esta parcialidad no se debe saldar con la inactividad o con una propuesta ruskiniana de nuevo cuño, sino con la inflexión compleja que recae sobre esta definición de patrimonio como ecología que estoy proponiendo, y que la superpongo con los mismos términos con que utilizará Ernest Fischer su "Necesidad del Arte". Decía el que fuera Ministro de Educación en el gobierno Renner en la Austria de 1945, que "El arte es el medio indispensable para esta fusión del individuo con el todo. Refleja su infinita capacidad de asociarse a los demás, de compartir las experiencias y las ideas". Más adelante, decía que, "El arte es necesario para que el hombre pueda conocer y cambiar el mundo. Pero también es necesario por la magia inherente en él".

El arte, el patrimonio, como vemos no son sólo bienes, son necesidades y lo que no llego a saber muy bien si son escasos. Es decir, hasta qué punto les amenaza su desaparición. Lo que sí queda claro, es que si esto ocurriera, algo que caracteriza a la cultura, su potencial de cambiar las cosas, nos condenaría al eterno presente, y también al interminable retorno.

\title{
LÍMITES DE LA INTERVENCIÓN EN EL PATRIMONIO HISTÓRICO: SU EXPLOTACIÓN ECONÓMICA
}

Por tanto, pensar el patrimonio nos obliga a meditar sobre los tres tiempos: pasado, presente y futuro.

Pero volvamos con Rimbaud: "no pensamos, nos piensan". Nos recuerda también al aforismo del antropólogo Levi-Straus: "los mitos piensan a los hombres".

Pues bien, cualquier reflexión sobre el patrimonio deberá pasar por interrogarnos sobre nuestro momento cultural, pues es éste el que nos condiciona con sus valores y apreciaciones, con sus movimientos y condición.

Podría construirse un juego de palabras entre Rimbaud y Straus: "El momento cultural nos piensa". En efecto, qué hacer con nuestro pasado y presente, depende y dependerá de nuestra visión, de nuestra mirada, de nuestra condición. No caben neopositivismos en esa auscultación sobre lo que nos pertenece a todos, pues este "todos" sólo somos nosotros, los que habitamos este presente.

Una vez centrada la clave desde la que se explican tanto el arco que va desde una argumentación sobre el pasado, hasta las ideas de la intervención arquitectónica a lo largo de los años, sería bueno comenzar por caracterizar el momento presente, sus aventuras y desventuras, sus seguridades e incertidumbres. Un ligero repaso sobre lo que opinan los filósofos de la cultura contemporánea nos ofrecerá la relatividad de nuestras visiones, las garantías de nuestro pensamiento, así como las sombras que nos confunden.

"La heterogeneidad" de voces, de géneros, de afirmaciones y corrientes culturales, podría identificar a nuestra época con el concepto de RAÍZ, inicio y origen, en vez de definirla con la idea de final y Apocalipsis. No hay más que recordar que en "un principio fue el caos".

F. Jameson, identifica estos signos de lo diverso con una pauta cultural en la que caben la coexistencia de rasgos muy diferentes e incluso subordinados entre sí. Su visión marxiana de la realidad justifica estos lazos que serían propios de los efectos de "la lógica cultural del capitalismo avanzado".

J. Baudrillart, ve en esta existencia poliédrica la correspondencia con una indefinida gama de ideales, fantasías, etc.

\author{
José Morales \\ Arquitecto
}

\section{Patrimonio es la ecología de pensarnos en un entorno que nos}

pertenece. 


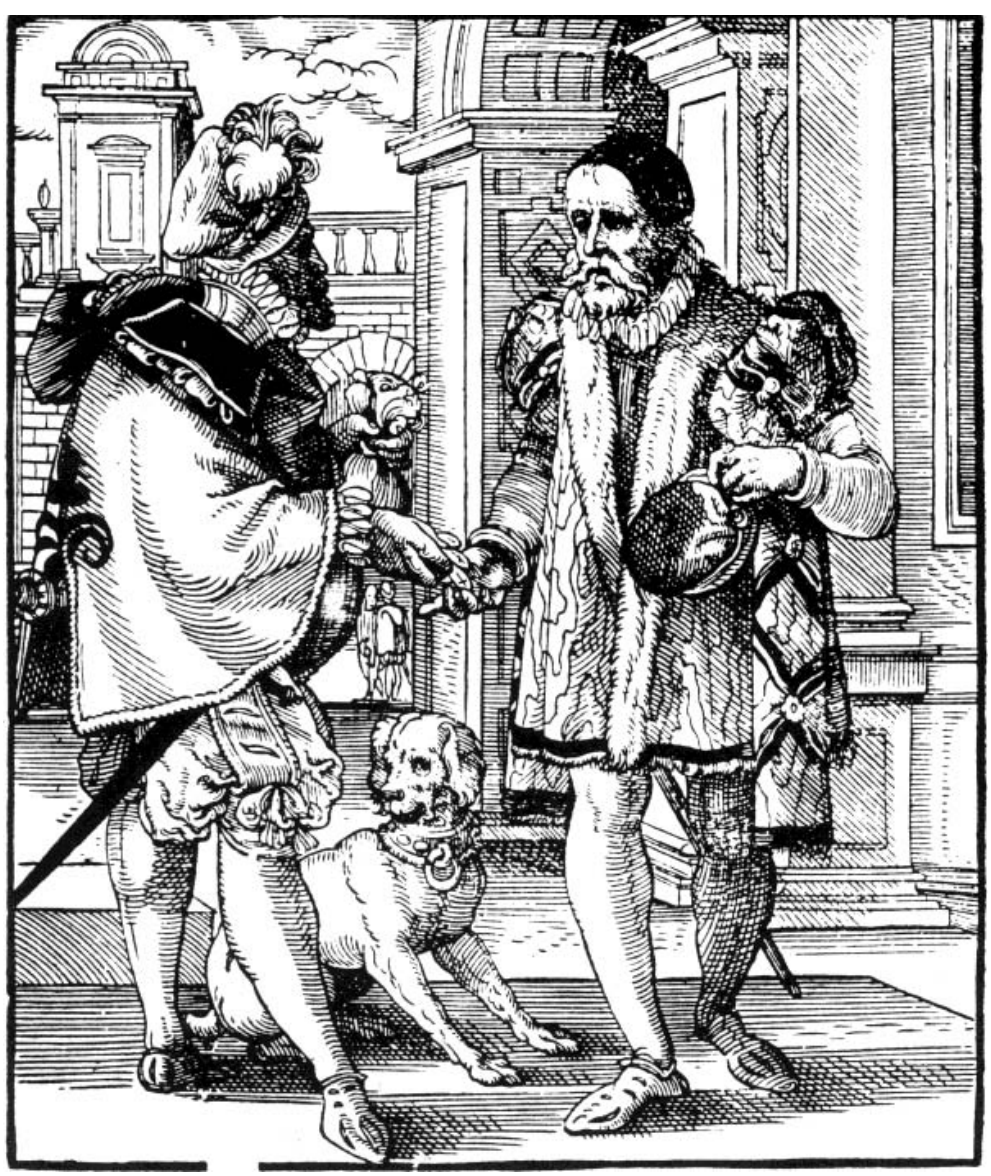

¿Están acaso en el mismo plano de discusión el

Patrimonio y su rentabilidad?
Esta multiplicidad, que se convierte en objeto de su último estudio, sería resultado de la mentalidad y apatía que se producen en el hombre del Fin de Siglo. En este mismo sentido es muy revelador el trabajo de E. Subirats sobre la "cultura como espectáculo". La cultura, los comportamientos sociales, los ideales, etc., tienen su referencia en el espectáculo como vía, y a veces como fin.

También, es probable que G. Simmel entreviera, antes de tiempo, algunas de estas pautas sociales al detectar como aquel "enrolarse en la banalidad", propio del comportamiento del hombre de la ciudad, era consecuencia de la condena de aquél a una indolencia, fruto del "embotamiento frente a las diferencias de las cosas" y su heterogeneidad.

Para G. Lipovetsky estas apariencias de lo diferente provocan un descentramiento, disuelven la centralidad, en tanto que última fuga del pensamiento, que abocan inevitablemente hacia una disipación de lo verdadero y lo falso. En este sentido no resulta casual, que en este tiempo en que vivimos, el de la postmetafísica, no nos preocupamos por el ser, sino por su comportamiento, su carácter, así como por un mostrarse frente a la cultura y a lo social.

De todo ello puede extraerse una consecuencia positiva en tanto que el sujeto parece estar al final de los interrogantes que enmarcan la cultura contemporánea. Es a él y a pensarse en la colectividad, en quien confluye la discusión sobre su entorno, su paisaje, su patrimonio. El sujeto es cuenco de experiencias, es emanador de propuestas que, justo originarse desde él, nos remiten a la colectividad. La colectividad es jugada en el entorno del sujeto.

Este pensamiento se refuerza en el crecer de la colectividad y su conciencia. Escribía Tapies que: “...la necesidad y por tanto el deseo de tener cerca de nosotros los objetos bellos, antiguos y modernos, que nos vivifiquen y nos acompañen en nuestras angustias e inseguridades nos parece que está lejos de perder el sentido. Es obvio, que una idea de la cultura más digerible y ecléctica, hoy interesa, tal vez más que a nadie, a las llamadas industrias culturales del beneficio. Eso no quiere decir, sin embargo, que ahora tengamos que considerar todo el mundo industrial como obra del demonio, o como decía machado, que la cultura no puede viajar en las alforjas de los comerciantes".

Con anterioridad, hemos mencionado la idea de patrimonio con la de ecología. En esa misma idea están la de la cultura como ocio fruto de la experiencia estética generalizada, fuertemente vinculada a la fiesta, cuya eficacia social proviene tanto de la belleza como de la funcionalidad. El arte, la cultura, el ocio como patrimonio sería la fiesta donde la comunidad se pone a prueba.

Goethe en su "viaje a Italia" a propósito del circo romano de Veron habla del pueblo como de un "monstruo con mil cabezas y mil cerebros", que primero vaga y ondea, y luego se reúne para el espectáculo y se transforma entonces en objeto de espectáculo para sí, "estando como reunido en un noble cuerpo, una única masa, una sola figura animada por un solo espíritu".

El patrimonio, según esta visión goethiana, podrá denominarse "popular" cuando sea capaz de crear los acontecimientos por los que el pueblo tome conciencia de sí mismo.

Decía Mikel Dufrenne en su "arte y élite", que si ha sido necesario Ictinos para edificar el Panteón, el desfile de las panateneas es el que convierte en realidad al monumento.

Nuestra concepción del patrimonio se va haciendo más compacta, más densa pero también más general, que no diluida, más vinculante, aunque no única condición de la cultura.

Es necesario enfocar o dirigir nuestro interés por el patrimonio junto a la de una estética de lo frecuente, de lo ordinario en el que confluyan patrimonio y vida.

Una vez realizada esta introducción general sobre mi idea de patrimonio y un entendimiento del mismo ligado al de la colectividad, es obligado referirme de modo más concreto, por mi condición de arquitecto, a mis juicios sobre la intervención en el patrimonio, y aquí, sí me refiero al que nombramos como "arquitectónico". 
El reto que nos ofrece cualquier proyecto de intervención nos sitúa frete al reconocimiento de lo que denominamos "hábito". El hábito podría definirse como la unión entre la idea de tiempo y la idea de presente. Este es el horizonte en el que se mira el proyecto.

La primera consecuencia de esa fuga hacia los contrastes del tiempo, nos obliga al difícil trabajo de olvidar las convenciones, es decir, ser conscientes de las mismas. Los problemas de la intervención nos remiten a un quehacer muy unido a la trasgresión del principio de identidad. El sabernos en esta vulneración de lo conocido nos sitúa en el entono, de nuevo, de la creación artística; se produce una confluencia, sin quererlo, entre arte y proyecto de intervención.

Desde Michel Foucault sabemos que existe la dualidad irreductible entre las palabras y las cosas. Entre las imágenes y las historias, entre la vista y el lenguaje.

La actividad del artista es muy próxima, en este sentido, a la del arqueólogo: éste desentierra palabras escritas sin sentido ni autor, dice J. Luis Pardo. El vértigo de esa búsqueda que se nos presenta desde la disociación entre lo aparecido y la realidad ya pasada, provoca la necesaria urgencia del arqueólogo por el nombre, por la tasación, por la enumeración, por el recuento. La identidad se encuentra perdida en el pasado, y por tanto entramos de lleno en el origen de los discursos y la interpretación. Las historias comienzan, por ello, justo con un acto creativo que más que recomponer, interpreta, y que más que datar, comenta. Es la modificación del origen la que provocó la exégesis, la traducción.

Ese adentrarse en el pasado del arquitecto, sitúa la intervención como actividad en esa relación perversa del espacio y del tiempo, que necesariamente provoca que nos arrojemos a esa época con nuestras interpretaciones, con nuestra cultura. La aventura en el pasado nos ofrece un paisaje sin centro, de relaciones extrañas, ambiguas que no llegamos muy bien a entender, si es fruto de nuestra condición presente, o bien debido a la desaparición de los objetos en sí.

En ese lanzarnos al pasado, más que edificar, desmontamos, más que conectar historias, las deconstruimos. Danilo Magris decía que el viajero es uno que deconstruye paisajes y que más que hacer, deshace. Pues bien, el arquitecto en ese trayecto hacia el pasado es un viajero, alguien que se agarra al solipsismo como condición para el descubrimiento de los argumentos, de las historias. Este viaje no encierra sino la imposibilidad de la conquista del tiempo, a menos que aceptemos que esa búsqueda del tiempo perdido se tiña, o bien de los inventos de Proust, o aparezca como pura necrópolis, lugar de la muerte, de lo corrupto, en palabras de Flaubert. Todo ello no quita la pasión del hombre por la ilusión del comienzo, del origen, aunque sólo sea por la tendencia a razonar sobre el caos, a encerrar lo azaroso en los límites de la ciencia y la razón.

En este campo de maniobras, no contamos con el horizonte cerrado de Viollet-le-Duc en materia de intervención arquitectónica, o el del romanticismo literario de Ruskin, que provocó el "odium teologicum" hacia la intervención. Tampoco estamos ya en ese despegarse de la historia de C. Boito provocado por el desprestigio del eclecticismo histórico.

La intervención hoy, se juega desde nuestra conciencia cultural, desde la que apreciar la relatividad histórica inserta en el discurso de la cultura como lenguaje, en el que palabras y cosas se han disociado, separado, como ha insistido M. Foucaut.

Es justo desde estas consideraciones desde las que afrontamos con optimismo el reto de una idea de explotación económica del patrimonio, pero también desde donde hemos de poner improvisación, una medida siempre útil es pedir el "tiempo muerto" en nuestra reflexión para el pasado.

Recordemos, por último, que estamos inmersos en esa aventura moderna que como un Eros misterioso y perverso, pone en complicidad todas las cosas heterogéneas. Así, podíamos finalizar preguntándonos: ¿acaso están en el mismo plano de discusiones el patrimonio y su rentabilidad?

\section{Aceptemos, por tanto, la heterogeneidad.}

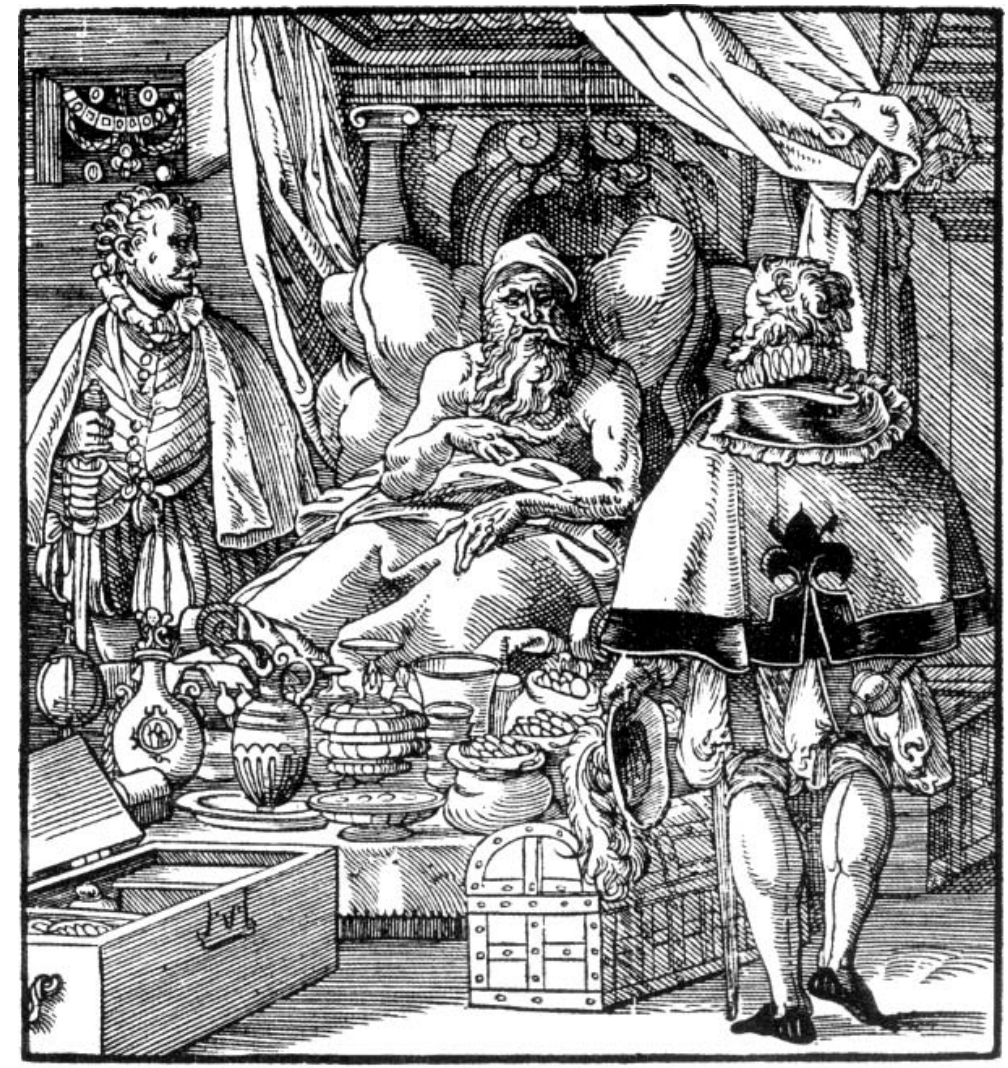

